\title{
Espiridião, o carnaval e uma estética do moderno na Florianópolis de Salim Miguel
}

\author{
Espiridião, Carnival and a Modern Aesthetic in Salim Miguel's Florianópolis \\ Espiridião, el carnaval y una estética de lo moderno en la Florianópolis de Salim Miguel \\ Natan Schmitz Kremer \\ Alexandre Fernandez Vaz
}

\section{Resumo}

Neste artigo, analisamos algumas chaves provocadas pelo conto "Carnaval: casos de Espiridião", narrativa que compõe o livro de estreia de Salim Miguel, Velhice e outros contos, para construir um quadro que se ocupa tanto da imagem de Florianópolis que nele está amalgamada quanto da própria experiência modernista na qual a obra se insere. Assim, discutimos alguns aspectos da cidade que se moderniza e em como esses elementos aparecem, primeiro, em um plano discursivo, o que aponta para uma série de contradições que nos faz atentar à forma. Nessa análise, apontamos para como o conto mimetiza a estrutura dual das elites da cidade e, ao mesmo tempo, impõe, pela montagem, a presença do modernismo como possibilidade de diferenciação.

Palavras-chave: Salim Miguel, Florianópolis, Modernismo, modernidade.

Abstract

In this paper, we analyze some special topics in the short story "Carnaval: casos de Espiridião," a part of Salim Miguel's debut book, Velhice $e$ outros contos, in order to construct both an image of the Florianópolis fused in the narrative and of the modernist experience in which the text inserts itself. Thus, we discuss some aspects of the city in its modernizing process, and how such elements appear, first, on a discursive level, which points to a series of contradictions, then we pay attention to literary form. In this analysis, we point out how the story mimics the dual structure of the city's elites and, at the same time, imposes, through editing, the presence of modernism as a possibility of differentiation.

Keywords: Salim Miguel, Florianópolis, Modernism, modernity.

\section{Resumen}

En este artículo analizamos algunos temas propuestos por la lectura del cuento Carnaval: casos de Espiridião, narrativa que compone el libro debut de Salim Miguel, Velhice e outros contos, en el cual intentamos construir un cuadro que se ocupa de una imagen de Florianópolis, así como de la experiencia modernista en la cual se inserta la obra. De este modo, discutimos algunos aspectos de la ciudad que se moderniza y como esos elementos surgen primero en plan discursivo, lo que nos lleva a percibir una serie de contradicciones que nos hace preguntar por la forma de la narrativa. En este análisis, discutimos como el cuento mimetiza la estructura dual de las elites de la ciudad y, a la vez, impone, por el montaje, la presencia de la vanguardia como posibilidad de diferenciación.

Palabras-clave: Salim Miguel, Florianópolis, Vanguardias, modernidad.

\footnotetext{
* Universidade Federal de Santa Catarina (UFSC), Florianópolis, SC, Brasil. (Dorcid.org/0000-0002-6085-5057. E-mail: natan.kremer@gmail.com

** Universidade Federal de Santa Catarina (UFSC), Florianópolis, SC, Brasil. (Dorcid.org/0000-0003-4194-3876. E-mail: alexfvaz@uol.com.br
} 


\section{Modernistas}

A cidade de Florianópolis encontrou seu modernismo no final dos anos 1940, impulsionado pelo Grupo Sul. Tendo como principal veículo de divulgação a Revista Sul, publicada entre 1948 e 1957, seus integrantes contribuíram também com o teatro e as artes plásticas, além de publicarem diversos livros pelas séries editoriais promovidas pelo periódico, os Cadernos Sul e as Edições Sul. O movimento travou pelejas com a intelectualidade estabelecida da cidade, opondo-se à estética parnasiana da Academia Catarinense de Letras e ao discurso oficial do Instituto Histórico e Geográfico de Santa Catarina, tanto em plano estético quanto em disputas por tal estética em jornais da cidade.

Salim Miguel, principal expoente do movimento, nasceu no Líbano em 1924, mas logo migrou com a família ao Brasil, onde residiu em pequenas cidades próximas a Florianópolis, tendo fixado residência na capital do estado no começo dos anos 1940. Já no primeiro momento, foi o principal representante do movimento, publicando três obras pelas Edições Sul, produção que ganhou fôlego posterior, chegando inclusive a ter o conjunto de sua obra agraciado com o prêmio Machado de Assis, da Academia Brasileira de Letras.

Uma olhada panorâmica à sua obra mostra que há uma constante elaboração da experiência de Sul em textos posteriores, o que é, talvez, expressão de um trauma pela ruptura modernista, ruptura esta que o levou à prisão. É o que diz em suas memórias sobre o golpe de 1964, quando não titubeia em compreender o feito como resultado de seu posicionamento estético (Miguel, 1994). Isso dá algo da intensidade da ruptura causada na Florianópolis de meados do século, aquele espaço de estreia, mas também de inspiração. É justamente na forma como essa Florianópolis emerge na primeira obra do autor, o compilado Velhice e outros contos (1951), que nos detemos, atentando a alguns aspectos da forma como amalgama no conto "Carnaval: casos de Espiridião" a cidade em modernização.

Nas páginas que seguem não realizamos apresentação sequencial da narrativa, mas tomamos algumas chaves provocadas pelo conto para construir um quadro que se ocupa tanto da imagem de Florianópolis quanto da experiência modernista de Salim e seus colegas na vida intelectual da cidade. Começamos pensando na modernização de Florianópolis e em como esses elementos aparecem no conto. Mas, ao focalizar algumas contradições da narrativa, principalmente nas considerações sobre a população negra, partimos ao estudo da forma textual, apontando para como o autor mimetiza uma dualidade das elites da cidade, impondo, pela montagem da narrativa, a presença do próprio grupo do qual faz parte como a possibilidade da diferença. A consequência da leitura que propomos é um texto que realiza uma espécie de ir e vir, em que muitos dos argumentos reaparecem ganhando nova camada interpretativa. Contamos com a colaboração de quem nos lê em não se apressar nas conclusões - algo muito semelhante ao que exige o próprio conto.

\section{A cidade}

“- Ah, não, não, mas você o deve conhecer, é impossível que não, todos o conhecem, todos, figura popular..." (Miguel, [1951] 1981, p. 3). Esta é a abertura do conto "Carnaval: casos de Espiridião", a trama mais urbana de Velhice e outros contos, cujo enredo corre o Centro de Florianópolis em uma noite de carnaval. A narrativa se constrói em movimento, pelos personagens que caminham pela cidade produzindo, com isso, uma percepção do processo modernizador tanto na esfera urbanística, pelos elementos de infraestrutura, quanto pela sensibilidade e pelas questões modernas que acometem os personagens.

A trama, mais ou menos simples, trata de um encontro entre o narrador que, retornando de uma visita a um amigo enfermo, encontra em uma rua pouco movimentada um conhecido, vendedor ambulante que concluíra suas atividades laborais do dia. Este começa a contar histórias, pede para que o narrador faça um esforço, que se lembre de Espiridião Facada, figura popular da cidade, sobre quem o primeiro sublinha não recordar. Na rua pouco movimentada, o narrador perde-se em divagações, mantendo um diálogo que não havia planejado e no qual parece não querer se alongar. Sujeito mais velho, sente as varizes, as pernas cansadas, quer voltar ao hotel 
(que, à época, mantinha uma estrutura que hoje chamaríamos de pensão) em que vive. Não consegue. "Insignificante, medíocre, a voz chegava. E eu fingia escutar, numa covardia sem nome" (Miguel, [1951] 1981, p. 4). Mas tentava, esforçava-se, algo sempre fazia com que voltasse a prestar atenção na conversa (quase um monólogo), mesmo que na continuidade retomasse um tom introspectivo de devaneios que não se relacionavam com os causos contados pelo colega.

Há, entretanto, um novo movimento nesse processo de perder-se - neste caso, um processo muito diferente daquele que Walter Benjamin (2017a) narra em suas memórias berlinenses, em que deixar-se perder é o desafio. Não mais pelo que lhe passa pela mente, o narrador começa a distrair-se pelos estímulos que lhe chegam do exterior, deixando novamente de acompanhar a história contada pelo personagem:

Um preto enorme, todo de vermelho com listras pretas, uma bengala na mão esquerda, na direita um cartaz onde estava escrito:

\author{
HOJE \\ Segunda apresentação dos \\ UNIDOS DA LAGOA \\ A maior "Escola de Samba" da terra \\ Prestigiem! \\ NÃO PERCAM... \\ tudo em letras garrafais (Miguel, 1981, p. 5).
}

Na sequência, surge outro grupo, vindo de outra esquina, representando outro bairro, com três homens negros, anunciando a Unidos da Princesa, o grupo rival. E dessas esquinas, cada escola de samba vindo de uma diferente, seguindo os homens e suas placas, começam a aparecer grupos fantasiados com suas músicas, tomando a rua, dando-lhe movimentação, "braços, mãos, rostos, pernas, corpos [...], mais cantorias, travestimentos" (Miguel, 1981, p. 6). O que o companheiro conta ao narrador é interrompido pela explosão de imagens que rompem o espaço urbano, cortando o monólogo do personagem e construindo a narrativa por meio de um jogo de sobreposição. Quando as imagens externas, os carnavalescos, cortam o caminho do narrador e de seu colega, eles passam a seguir os grupos, acompanham a "multidão", caminham pela cidade, observam o urbano, percebem os foliões. O companheiro não para de falar, vai de assunto a outro, a história original sobre Espiridião se esvai. Os corpos, contudo, continuam caminhando, seguindo os festejos até chegar à praça.

A narrativa se constrói, então, por um jogo de sobreposições entre falas, imagens e crítica. Há uma dupla narração ao longo do conto, com o narrador-oficial, aquele que dá voz ao texto, que seleciona falas, costura imagens, finaliza o escrito, mas também com o personagemnarrador, responsável pelas cenas de diálogo ao longo da narrativa. Elas serão ora interrompidas pelo narrador-oficial, ora ignoradas, ao perder-se ele em imagens da cidade, sem atinar ao que o colega fala, ora confrontadas diretamente, negando o que este diz. Assumimos, então, as seguintes categorias, já que os personagens não são nominados: ao narrador, chamaremos de narrador-oficial; ao personagem que narra, personagem-narrador.

\title{
Florianópolis
}

Se é no espaço urbano de uma Florianópolis em transformações que a trama se desenrola, não parece equivocado questionar os processos de modernização da cidade, marcados por reformas políticas, urbanísticas, sanitárias e arquitetônicas desde fins do XIX, o que se expressa também na produção de discursos científicos e morais que reconfiguram a sensibilidade e a constituição de subjetividades correspondentes a esse novo tempo. Ou seja, duas instâncias se vêm em transformação concomitante e mutuamente determinada: por um lado, a estrutura da cidade; por outro, a subjetividade dos que nela habitam.

Foi por meio de um "cientificismo médico-higienista que [se] pôs em funcionamento uma série de práticas e discursos que formaram uma imagem desqualificada da população da ilha e do litoral catarinense" (Araujo, 1989, p. 13), que não integravam a nova elite composta, sobretudo, pelo funcionalismo público. Os saberes ligados à cura, até dado momento sob os 
cuidados de práticas tradicionais, passam a ser controlados por médicos e hospitais. As crenças vão sendo estigmatizadas e partos passam a ser realizados em maternidades, as ervas medicinais vão perdendo sua relevância social e a cura das doenças agora é procurada nos remédios que se encontram à venda em farmácias (Motta, 2015).

A ideia de uma sensibilidade moderna ligada às condições materiais foi tema das análises de Benjamin (2017b) sobre a modernização dos centros urbanos, Paris e Londres principalmente. O flanêur a caminhar em passo de tartaruga é resultado também da constituição das vitrines que colocavam a mercadoria em exposição, resultado de uma arquitetura que tinha como matéria prima o aço e o vidro. A sensibilidade moderna responde à experiência da cidade, que não é equiparável entre as grandes metrópoles. Os estudos de Benjamin mostram a aglomeração e o "atropelamento" das massas (por outras massas) na Londres de Poe, o que não se reflete na Paris de Baudelaire, onde a conexão de uma rua a outra, por meio das passagens, evita a aglomeração e convida à redução do passo. O que Benjamin sugere é a atenção às especificidades da estruturação do urbano, que acabam por resultar em subjetividades distintas. Pensar a cidade não é processo de transferência de categorias para contextos que não se sustentam (Sarlo, 2013), mas a compreensão da organização do tempo e do espaço nas particularidades que se mostram, também em seus habitantes.

As mudanças em Florianópolis, especialmente nas três primeiras décadas do século $X X$, não são isoladas, mas acompanham o processo de urbanização nacional que ganhara corpo no período prévio à abolição da escravatura, nas três últimas décadas do século XIX, intensificando-se na Primeira República. Hermetes de Araújo (1989) observará, contudo, que o fluxo migratório ao urbano que marca o Brasil nesse período não se dá em Florianópolis, onde houve inclusive declive populacional entre as décadas de 1920 e de 1940. Mesmo sem seguir o movimento de expansão da população nas cidades, a Ilha de Santa Catarina, sobre a qual a capital do estado estava instalada, passou por uma série de transformações urbanas.

As redes de água encanada datam de 1909, a iluminação pública por energia elétrica começa em 1910, a construção da primeira rede sanitária termina em 1917. Em 1922 viu-se o asfaltamento da primeira avenida, a Hercílio Luz, seguido pela inauguração, quatro anos depois, da primeira ponte que liga Ilha e continente, construída sobre um estreito em que outrora se realizava o transporte por barco. O que se coloca é que Florianópolis como cidade recebe o que se postula em termos de política nacional, mas não na forma de uma cópia ou de um espelho do centro, senão como construção de um projeto de urbanização no qual se colocam em cena as dinâmicas e interesses da cidade - e que, como tal, não é reprodução, mas inclusive uma possibilidade de que a periferia fale ao centro (o que se evidencia na discussão final do texto, sobre Marques Rebelo). É decorrente disto que cabe a pergunta pela forma como a literatura de Salim Miguel compõe estes elementos do processo modernizador da cidade; perguntar por Florianópolis é, aliás, perguntar, também, por uma ideia de Brasil.

O conto se passa provavelmente na Praça XV de Novembro, onde duas escolas de samba, Unidos da Lagoa e Unidos da Princesa, se encontram. Na verdade, é lá que a vida na cidade se encontra, com cafés, bares, a sede do Partido Comunista, na década de 1940, além dos cinemas que entretinham a população já desde a década de 1930. Após a exibição das películas, era na Praça XV que o footing acontecia, criando sociabilidades, tornando a ida ao cinema, divertimento das massas, em prática social. Mas também reforçando a desigualdade étnico/racial, com ruas para negros e brancos fazerem o footing separados depois da sessão (Vieira, 2010). Trata-se, então, de espaço geograficamente reduzido, com população numericamente baixa, em cidade periférica e racialmente segregada. Há mais um elemento para compreendermos a estruturação de Florianópolis a meados do século XX. Sérgio da Costa Ramos destaca uma interpretação que sugere certa dualidade na cidade. Escreve:

O mundo dual de Floripa se nutria da grande "matriz" dos partidos políticos. O PSD dançava no Clube Doze, tomava café no Bar Rosa, torcia nos gramados pelo Avaí e nas raias pelo Martinelli. A UDN valsava no Lira, tomava a rubiácea no Bar do Quidoca, bramia nos estádios pelo Figueirense e, nas águas da baía Sul, exaltava-se pelo Aldo Luz. E 
se o PSD lia O Estado, a UDN usava-o para embrulhar tainha, lendo A Gazeta ou o Diário da Tarde (Ramos apud Vieira, 2010, p. 37-38).

Se a cidade parece dividida em dois blocos, algo semelhante acontece com o carnaval. No levantamento de Átila Ramos (1997) vemos a presença dos bailes no Clube Doze de Agosto e no Lira Tênis Clube, clubes sociais que dividem a elite florianopolitana. O autor destaca, entretanto, a Praça XV, local em que os membros das duas associações se encontravam ao sair do baile de salão e partir ao carnaval de rua. Ora, a rua é aquele lugar que "recorda, embora de maneira intermitente, que a intempérie existe e que nem tudo está sob controle" (Sarlo, 2013, p. 66). É na rua que os associados dos clubes perdem o respaldo dos pares e encontram o outro lado da dualidade, os membros do clube rival, que liam o outro jornal, que torciam pelo outro time (de futebol, de remo), que votavam no outro partido. A rua traz à cena a divergência; misturando gente, oferece a possibilidade do conflito.

\section{Contradições}

O carnaval como prática social já era antigo na cidade. Acompanhando Oswaldo Rodrigues Cabral encontramos uma série de experiências urbanas ao longo dos dias dedicados aos festejos, fortemente marcadas pela desigualdade, tanto de classe quanto de raça/etnia. Ao referir-se aos limões de cheiro, mostra as reproduções de limões feitas de cera e recheadas com líquidos odoríficos que eram atiradas das janelas nas pessoas que passavam pelas ruas no carnaval. A atividade de prepará-los era de "muitas senhoras pobres, que expunham o produto 'nas lojas, tabernas, armazéns e outras casas'", e não se esquece de comentar que "negro não podia tomar parte na brincadeira - pudera!..." (Cabral, 1979, p. 228-229). Aponta, então, à segregação da cidade entre brancos e negros ao se referir ao carnaval na segunda metade do século XIX, o que, como mostra Cristiana Tramonte (1995), mantém-se nas primeiras décadas do século $\mathrm{XX}$, quando os bailes e danças de negros não podiam ser realizados no espaço público. A situação fez com que a população afrodescendente se organizasse em Sociedades de Bailes, em espaço fechado e privado, mas a autora nota também um novo componente moderno, o rádio, que passa a ganhar força a partir da década de 1930, apresentando à sociedade florianopolitana marchinhas e sambas produzidos especialmente no Rio de Janeiro.

Se já existia, então, uma sensibilidade ao gênero musical, parece ter sido a criação do $5^{\circ}$ Distrito Naval, em 1948, de grande importância na reconfiguração do carnaval florianopolitano. Na situação, uma série de marinheiros do Rio de Janeiro e do Norte do país vieram atuar em Florianópolis, fato do qual decorre a criação das primeiras escolas de samba da cidade (Tramonte, 1995). Chegando à Ilha, foi no Morro do Mocotó onde se abrigaram, local também habitado principalmente por descendentes de escravizados. O que Tramonte mostra é que a saudade do samba por parte dos cariocas, junto a um envolvimento com a população local, resultou na criação das escolas de samba. A velocidade é acelerada: tanto o $5^{\circ}$ Distrito Naval quanto a Protegidos da Princesa tem sua fundação no mesmo ano, 1948.

O movimento indica vetores diferentes: o aumento populacional das margens do Centro, a ocupação da Praça XV por essa população. E, na narrativa de Salim, está a velocidade de percepção das mudanças do urbano. "Carnaval: casos de Espiridião" foi originalmente publicado em 1951, três anos depois do surgimento da Protegidos da Princesa, que "desfilou" pela primeira vez em 1949. Mas, em seu momento de surgimento, essas escolas de samba tinham em torno de 30 participantes cada, o que expressa uma contradição histórica na assistência ao carnaval na cidade. Tramonte coleta dados do jornal O Estado, em edição de 1935, em que se fala da espera de 10 mil pessoas para compor os festejos no Centro da cidade, mas também mostra como há, em consequência da $2^{\mathrm{a}}$ Guerra Mundial, um processo de esvaziamento da celebração de Momo ao correr da década de 1940. Escreve: "Nesta época o carnaval de Florianópolis vivia um período de decadência, originado pelo clima depressivo gerado pela Segunda Guerra Mundial. É exatamente nesta brecha que irão penetrar os negros pobres de Florianópolis, associados aos marinheiros, para alguns anos após, hegemonizar o carnaval" (Tramonte, 1995, p. 79). O período de hegemonização ao qual a autora se refere é, evidentemente, a consolidação do carnaval em torno 
das escolas de samba, o que acompanha também um movimento que começa a se desenrolar na década de 1950, no qual o festejo volta a mobilizar parcelas maiores da população. Mas não é isso o que nos interessa no momento, senão as categorias que aparecem na narrativa de Salim Miguel ao se referir ainda ao pós-guerra.

O autor utiliza expressões como "seguir as massas", "acompanhar a multidão", em uma cidade de 50 mil habitantes, com zona urbana restrita, que vê o carnaval em declínio. A literatura da época nos oferece algo desse clima. Franklin Cascaes (2008, p. 28-29), contemporâneo de Salim, ao recolher rezas e benzeduras na década de 1950, destaca a diferença das pronúncias entre um bairro do Sul e outro do Norte da Ilha de Santa Catarina. Ao transcrever a benzedura de Cobrelo em Rio Tavares, mimetiza em sua escrita "fôgo salvagi"; em Santo Antônio de Lisboa, a mesma benzedura tem outra pronúncia: "fogo servage". As crônicas do folclorista mostram a manutenção de uma linguagem oral distinta em consonância a uma imigração proveniente de diferentes ilhas do Arquipélago dos Açores no século XVIII e em como o isolamento das comunidades afastadas do Centro da cidade e a falta de contato entre bairros fez com que as formas de linguagem mantivessem características próprias. Há, para além de uma população numericamente baixa, certa dificuldade de locomoção dentro da própria cidade, com poucas estradas, transporte (privado) marítimo restrito e frota de ônibus reduzida - como também a prosa de Cascaes (2012) apresenta.

Talvez o que esteja no fundo desse vocabulário empregado por Salim Miguel seja, então, algo de uma influência literária. Ao referir-se a Espiridião, mas também a outros "tipos populares", como Lagartixa, Babão, os irmãos João e Antônio Tolo, Treme-treme, o personagem-narrador comenta que se trata de "tipos para um novelista, Poe ou Dostoviewky" (Miguel, 1981, p. 9). Formula-se aí a ideia de toda a influência de uma literatura moderna que tem o urbano como questão. Mas esta não é a única forma em que a modernidade é retratada no conto. O narrador-oficial também faz entrever uma série de elementos; ele, que a nada quer reparar, comenta: "Eu já me sentia perdido em meio àquela massa informe. Não gostava de multidão, de amontoado. Amava o silêncio, a paz da solidão" (Miguel, 1981, p. 9). Se há certo descompasso ao longo da narrativa, como o exagero ao dizer "massas" e "multidões", talvez exista algo de função heurística nas categorias. O exagero aponta para uma nova estrutura do sensível na vida na cidade, que expressa questões latentes na nova dinâmica do urbano, mas também um desejo do moderno/do urbano, algo semelhante ao que, nos estudos de Beatriz Sarlo (2004) sobre Arlt e Quiroga, aparece sob a nomenclatura de "sueño": o desejo da técnica, do saber-fazer, uma imagem de progresso. Com isso, Salim torna sua narrativa um movimento histórico que aponta para as mudanças objetivas da cidade, mas também para o desejo do moderno como experiência subjetivadora. O exagero do olhar de Salim ao Centro de Florianópolis é expressão do posicionamento que o autor ocupa na cidade, posicionamento este que o leva a se afastar da estética naturalista de Gama D'Eça e da estética folclorista de Cascaes. Deixemos por um momento essas questões.

Na narrativa de Salim, a escola de samba Unidos da Princesa ganha uma rival, a Unidos da Lagoa, com a qual, ao longo do conto, trava disputas por voz e espaço, dualidades. Merece nota, entretanto, o fato de que a Copa Lord, segunda escola de samba de Florianópolis, tenha sido fundada apenas em 1955 (o conto é de 1951). Salim percebe certa dualidade da vida da cidade e, ao escrever sobre o carnaval, retoma tematicamente essa sensação. Trabalha com uma escola de samba existente e cria ficcionalmente outra para que sua narrativa expresse a divisão da cidade. Cada escola descendo de uma esquina, vinda cada qual de seu bairro, encontrando-se na Praça $\mathrm{XV}$, onde a música de uma sobrepõe-se à música de outra nas interferências que o narradoroficial percebe e que interrompem o monólogo do personagem-narrador. Esses elementos se dão ao se referir, porém, às escolas de sambas compostas por descendentes de pessoas escravizadas e imigrantes recentes. Salim, aparentemente, projeta em um grupo social marginalizado a experiência de dualidade das elites.

Uma olhada à poesia memorialística de Sebastião Ramos pode auxiliar a compreender esse processo. Em "No tempo do Miramar" o autor dedica uma seção aos clubes sociais de Florianópolis, com poemas sobre o Clube Doze de Agosto e o Clube Lira, aqueles que dividiam 
a elite dual da cidade. Mas, antes, há um no qual encontramos um comentário repleto de consideraç̃oses sobre o Flor do Abacate, outro clube de dança:

Flor do Abacate, tipo gafieira

onde frequentavam os pretos.

Não me lembro onde era,

acho que fica p'ros lados

da Conselheiro Mafra,

próximo da ponte.

Do sótão da casa da Jerônimo Coelho,

onde morávamos naquela época,

ouvia-se, vindo daquelas bancas,

o som de uma música bem cadenciada:

uma batucada (Ramos, 1999, p. 14)

Nos versos de Sebastião Ramos, vemos os ritmos da dança, a batucada, com outros instrumentos que produzem outro gênero musical, a gafieira. Mostram o distanciamento dessas práticas no espaço urbano, não no epicentro da cidade, mas lá p'ros lados da Rua Conselheiro Mafra, na cabeceira da Ponte Hercílio Luz que, embora cêntrica, é também um lugar afastado, às suas margens (em direção contrária ao Morro do Mocotó, onde residiam). Aponta, ainda, a segregação entre brancos e negros, ao mencionar um clube social etnicamente marcado, para um público específico. Mas o mais interessante é como nesses versos apenas um clube é mencionado para a população negra, enquanto dedica, na mesma obra, poemas tanto para o Clube Doze quanto para o Lira Tênis Clube, ao escrever sobre os divertimentos da elite. Parece que a hipótese da projeção equivocada, no conto de Salim Miguel, de uma experiência das elites sobre uma população marginalizada, se segura; a discriminação racial impossibilita a experiência da dualidade do urbano.

Salim escreve literatura. Sua preocupação não é produzir uma história da negritude em Florianópolis, tampouco um tratado sobre a relação entre migração e carnaval. O que seu texto faz é amalgamar a experiência do tempo. É composto pela percepção da mudança e da presença desses novos sujeitos por meio de suas práticas sociais, especialmente o carnaval. No processo, o autor realiza dois movimentos: ao situar-se no Centro da cidade, percebe a emergência de uma série de sujeitos apagados de uma "literatura oficial", especialmente daquelas estéticas preocupadas com o mar, como as de Othon Gama D'Eça ([1957] 2008) e de Franklin Cascaes (2012); e, ao perceber esses outros sujeitos, antecipa questões ainda apagadas nos escritos acadêmicos sobre Florianópolis, que ganharão estudo detalhado apenas uma década depois, com a publicação da obra de Fernando Henrique Cardoso e de Otavio Iani, Cor e mobilidade social em Florianópolis, em 1960 (Cardoso, 2000).

Essa preocupação de Salim com o Centro de Florianópolis pode ser resultado de dois fatores. O primeiro, autores e livros aos quais se dedica e que se preocupam com o urbano. É o caso dos já citados Poe e Dostoievski, mas também do existencialismo (Sartre, Beauvoir, entre outros), da psicanálise de Freud, além de contistas modernos de língua inglesa e francesa, como Hoffman, Maupassant, Mansfield, e romancistas de língua portuguesa, a exemplo de Eça de Queirós e Machado de Assis. Diversos deles foram mencionados em comentários críticos de Salim publicados na Revista Sul. O segundo elemento é um componente traumático em Salim. Ele, que não era negro, nascera no Líbano, pretexto que lhe gerou uma série de preconceitos raciais nas primeiras cidades em que residiu. Um fragmento de Nur na escuridão, romance memorialístico, dá algo do tom:

E de repente, sem qualquer explicação, sem lógica visível, sem nenhum fato aparente que justificasse ou provocasse, a reclamação dos demais comerciantes, solerte de início, escancarada a seguir, dois ou três ou quatro, nem meia dúzia eram, diziam, estamos sendo prejudicados, a queixa ao padre, esse estrangeiro, esse turco, chegou ontem e nos tomou a clientela, sem se lembrarem que também eles eram imigrantes, ou filhos ou netos de, passaram a chamar o pai de turco e gringo. Deslembravam-se de que eram chamados de galegos. $\mathrm{O}$ boicote começou. Maior a mágoa, acompanhada de decepção, quando ficou sabendo do sermão do padre nas missas dominicais, até nas novenas. Logo os fregueses sumiam intimidados, o padre recriminava-os, por que, em lugar de procurarem as casas de comércio dos conterrâneos, procuravam a do gringo? Pela primeira vez, sim, o pai tomava conhecimento desse termo, era 
assim tratado. Não "turco" - que já o deixava indignado, embora houvesse uma explicação. Não bastava o domínio turco que durante tanto tempo... tanto tempo... Aí o pai reconsiderava, raciocinava, virava-se para Tamina, para Hanna, havia sem dúvida uma certa lógica no "turco", a Turquia dominara seu país durante séculos. Agora, por que o gringo, para o qual não encontrava qualquer explicação? (Miguel, 2000, p. 98-99).

Dois elementos da constituição subjetiva de Salim influenciarão seu posicionamento modernista. Primeiro, a influência de uma nova literatura que tinha no urbano sua percepção e expressão estética. A influência parece ter levado o autor ao espaço urbano, encaminhando à cidade suas preocupações. Mas a experiência de subalternidade parece ter sido central para que, no urbano, Salim visse aqueles que não tinham espaço. Foi talvez sua experiência social, sua configuração como sujeito excluído, que lhe permitiu perceber a existência de uma cidade que se constrói pelo outro, que tem em sua estrutura a iminência do conflito. E que, como conflito, mostra a possibilidade da mudança dos agentes no campo do poder.

De alguma maneira é o que coloca George Didi-Huberman (2017) ao se perguntar pelos figurantes no cinema, quando indica o quanto da sensibilidade do diretor produz perspectiva diferente na forma de captar as imagens. Sem afirmar, o que expõe é que o lugar da preocupação social com aquilo que será captado expressa também o lugar do sujeito que produz a estética; não o fato de que o captável não existisse antes, senão o fato de que o lugar social do produtor (o escritor, o diretor) da estética faz ver o que, até então, havia sido construído como invisível. O que muda é mais um lugar do posicionamento do que uma ideia de "realidade", de "verdade". Não se trata de tomar a vida do autor como meio para explicar a obra (o que poderia cair em um discurso de representatividade, que acaba por anular o que é propriamente estético, ou pelo menos formal), mas de que a estética possa explicar algo da vida do autor. O ponto não é pensar em como a exclusão da vida intelectual florianopolitana sofrida por Salim o condiciona como autor ou condiciona sua estética, senão em quanto que o fato de Salim se posicionar em outro lugar social é expressão de sua figura em termos de uma história social, e o quanto deste lugar no qual Salim se posiciona pode falar dele mesmo, da construção de um sujeito por meio de uma leitura do trauma.

É talvez a mesma força que produz os "exageros" da estética de Salim. Se os hotéis da época se assemelhavam às pensões de hoje, é curioso reparar que outros narradores de Velhice e outros contos também vivem nesses estabelecimentos - é o caso, por exemplo, do narrador da trilogia Velhice. Em comum, argumentam uma ideia de solidão na cidade, de vida sem familiares, como que "perdidos" ao acaso em Florianópolis, mas, ao residirem em um hotel/pensão, estes narradores são chamados em seus quartos quando se demoram demais na sesta (na trilogia Velhice). Talvez esses narradores carreguem algo ambivalente que acaba por expressar a relação ambivalente de Salim Miguel com Florianópolis, capital do estado e, ao mesmo tempo, pequena cidade provinciana. Ele, que nasceu no Oriente Médio e migrou ao Brasil ainda na infância, residiu em pequenas cidades próximas à Ilha. A imagem de Florianópolis se constitui sob um conflito, uma espécie de memória da grande cidade quando nela não residia (isso aparece, por exemplo, em Nur na escuridão), mas, nela residindo, talvez perceba não se tratar de uma cidade tão grande assim, que não se assemelha tanto àquelas que lê nas obras literárias. A solidão que deseja o narrador, mas que não é expressão de um anonimato pleno, parece andar muito próxima a essa ideia de uma "massa" em uma cidade pequena - algo equivocado, mas que expressa a estrutura de sentimento do autor: a relação com Florianópolis, em Salim, é algo desfocada, conquista e promessa ao mesmo tempo conquista, em comparação ao já vivido; promessa, em relação a seu leque de influências que tem nas grandes cidades a fonte de sua literatura.

\section{Moderno/Moderno/Modernista}

Como vimos, Salim aparentemente se equivoca ao tentar plasmar a estrutura das elites nas camadas emergentes de cidadãos urbanos. Esse processo, porém, parece se dar de forma temática. A sua vez, como já escreveu Roberto Schwarz, a mímesis é um processo de reinvenção 
da estrutura social na estrutura textual em que, mais do que preocupação temática, há um processo no qual "forma literária e relação social injusta respondem uma à outra com rigor, de sorte que o exame de um polo implica a fixação de dimensões do outro" (Schwarz, 2014, p. 67). Trata-se de reinventar como estrutura textual aquilo que é estrutura social.

Assim, o lugar ao qual Salim chega pela mímesis formal é muito diferente das questões que aparecem no plano do discurso. Veja-se, por exemplo, que tanto o narrador-oficial quanto o personagem-narrador são sujeitos modernos, marcados ao longo de todo o conto por conflitos entre si. O personagem-narrador evoca Poe e Dostoievski, mas com tom folclórico. Fala em perceber tipos populares, em descrevê-los em uma obra literária. Mas o que seria o folclore senão um problema moderno de capturar o passado para que não se perca? Traz um jogo duplo, pois, se por um lado observa a ameaça da extinção, por outro não capta o movimento de transformação dado pelo tempo, tomando a história como algo estático, o que permite tomar o moderno como sinônimo de devastação. É o que constitui a obra do já mencionado Cascaes. Se em seus primeiros estudos buscava plasmar as benzeduras da Ilha de Santa Catarina, posteriormente em suas crônicas sobre as bruxas em Florianópolis, compiladas em $O$ fantástico na Ilha de Santa Catarina, passa a produzir toda uma crítica à modernidade:

A Maria Macária não via nada com bons olhos de amizade o namoro do filho com a tal bisca prosa, a Irineia das Dores. Ganhar uma namorada daquele jeito ou uma nora era, para a Maria Macária, um presente de valor mesquinho e inútil. A danada da Irineia tinha uns parentes cá pras bandas da cidade que eram que nem ela, metidos a arrogantes e importantes, mas que, no fundo da razão, não passavam de uns pobres-diabos que escaparam da roça através do auxílio de um chefe político, garimpeiro de votos para políticos estrábicos e primo segundo do tio dela. [...] O Bento Leandro era um homem simples, de costumes roceiros, o que não valia orgulho ou qualquer pretensão citadina, mas que também não queria opor qualquer tomada de justiça contra as extravagâncias da sua exótica e arrogante namorada. Até que ele a apreciava muito, principalmente quando ela se apresentava bem ensacada dentro de uma calça de brim descorado, exibindo o seu par de nádegas calipigianamente avantajadas aos olhos esbigalhados da população da comunidade dela. E, engolindo um a um os feitiços bruxólicos que ela copiava na cidade e exibia a ele, combinou casamento e casaram-se mesmo a contragosto da mãe dele (Cascaes, 2012, p. 217-218).

Ou seja, com sentido inverso ao da forma como Benjamin (2019) lê a potência da história, o folclore também é o passado posto como problema do presente, por si moderno. É a necessidade de capturar a tradição, mas em chave naturalista; ignora que algo possa resultar do movimento do tempo, é antialegórico, antidialético.

Voltando a Salim, na figura do narrador-oficial as questões modernas também se colocam. Aqui, já não como forma de percepção do passado, mas como prática social no presente. Simmel (2005) mostrou em seus estudos a transformação das sensibilidades na vida nas cidades, onde o tempo foi enquadrado pelo relógio, as trocas qualitativas pelo dinheiro, coeficiente universal de equiparação. Ao buscar analisar o problema pela chave das grandes cidades e da vida do espírito, mostrou que a vida marcada pela burocracia resulta em busca pelo anonimato. Se a cidade expressa estímulos constantes para o olhar, a atitude blasé por parte dos indivíduos é mecanismo para nela poder habitar; escolha do que ver, dada a impossibilidade de a tudo atinar. O tom, também moderno, marca as afirmações do narrador-oficial. Diz estar cansado, não querer prestar atenção, sentir-se perdido em meio à massa.

Ou seja, Salim parece mimetizar a estrutura dual da cidade nas vozes que dão forma ao texto. Claro que caberia questionar até que ponto as elites concorrentes eram tão diferentes entre si. A ideia não é sugerir uma UDN mais folclórica ou um PSD mais blasé. Entretanto, trata-se de dois grupos que buscavam ver o moderno e, por sequência, aquilo que era bárbaro. Isso se repete em Salim: o narrador-oficial, em seu tom blasé, prefere não ver; o personagemnarrador vê, mas com olhos que exotificam. Salim parece construir, na estrutura do texto, duas figuras que percebem a cidade moderna, mas que, em suas práticas, de alguma maneira guardam um afastamento da consequência desse moderno - o modernismo; na cidade moderna, essas metamorfoses dos representantes das elites querem manter algo do poder 
oligárquico que sempre detiveram. São figuras opostas, mas que realizam movimentos muito próximos. Uma olhada à vida intelectual catarinense em meados do século XX nos auxilia a compreender algo do que Salim mimetiza.

A questão que vem à tona no cenário intelectual do estado ao final da década de 1940 é a reconstrução discursiva da descendência açoriana como elogio, estratégia política que estava preocupada com a promoção de uma imagem positiva do litoral catarinense em detrimento do interior de Santa Catarina, marcado pela colonização alemã e italiana. No fundo do argumento está a preocupação com a manutenção política de Florianópolis como capital do estado, posto este que se via ameaçado pelo progresso econômico de outras regiões. Maria Bernardete Ramos Flores (1997), ao discutir as polêmicas que envolvem a Farra do Boi, prática de origem açoriana que se constitui na caça ao boi solto, mostra o posicionamento de dois importantes intelectuais da época: Othon Gama D’Eça e Oswaldo Rodrigues Cabral.

Gama D'Eça, escritor naturalista da Academia Catarinense de Letras, ocupava, em 1948, o posto de Secretário de Segurança do governo de Aderbal Ramos da Silva, filiado ao PSD. Flores (1997) mostra que o responsável pela pasta baixou, nesse ano de 1948, uma portaria na qual proibia a prática da Farra do Boi, o que coloca quase que uma contradição à sua estética que, como se pode ler em Homens e algas ([1957] 2008), apoia-se no naturalismo para produzir uma relação de determinação do homem pelo meio - no caso, pelo mar; um indivíduo sem ação, sem desejo. Cabral, deputado pela UDN - fundador do Departamento de Antropologia da Universidade Federal de Santa Catarina, membro do Instituto Histórico e Geográfico de Santa Catarina -, apresenta postura semelhante em seu livro Nossa Senhora do Desterro, no qual, ao falar da Farra do Boi, mostra que tal prática, em Florianópolis, era uma "deturpação" (categoria do autor) daquela realizada nos Açores, que aqui assumia "um misto de perversidade e de covardia" (Cabral, 1979, p. 238). Assim, a população açoriana retratada por Cabral, que era vista como "portadora de uma civilização", é também vista, quando se refere à Farra do Boi, como "portadores de "laivos bestializados'" (Flores, 1997, p. 139). As elites de Florianópolis, que se propunham muito duais e diferentes entre si, bastante se aproximam quando de um discurso civilizatório das práticas na cidade moderna.

Assim, toda a suposta dualidade da cidade é, na verdade, expressão de um movimento muito comum, como aquilo que dá forma à narrativa de Salim Miguel: dois personagens que aparentam opostos, mas que em verdade não são tão divergentes entre si (que, entre Gama D'Eça e Cabral, por motivos diferentes, acabam por concordar com a extinção da Farra do Boi). Só que no modernista parece existir um novo elemento, uma nova questão: a presença, justamente, do "novo". Em descompasso com o establishment intelectual da cidade, Salim mimetiza a presença dos dois grupos das elites, mas produz seu argumento como que fora do discurso afirmado por ambos, em um ponto chave: a montagem da narrativa. Vejamos um fragmento:

- Vamos comer qualquer coisa, estou com uma fome de mil diabos. Mais tarde voltaremos aqui para assistir à última parte. É quando descerá para o desfile final, como surpresa, toda a negralhada. Dos morros, das imediações. Hoje não é nada. Amanhã, último dia, sim. Que espetáculo! Você não viu nada. Deixe que baixem os verdadeiros negros do morro, eles sim, que guardam a tradição de antigos ritos africanos, que fazem de tudo um fim sagrado, feiticeral. Os rituais, pois são verdadeiros rituais... são insubstituíveis no carnaval, sem eles não há carnaval verdadeiro, já o trazem no sangue [...].

- Mas eu não sei a que vem e... tento (Miguel, 1981, p. 13-14).

O personagem-narrador emite comentário caricatural sobre a presença de componente biológico na "raça" negra, o que lhes tornaria mais "propícios" ao carnaval, e o narrador-oficial, que aparentemente não concorda, busca elaborar uma resposta. Não há, porém, qualquer oposição textual. A crítica de Salim ao racismo que aparece na fala do personagem-narrador se dá por meio da montagem da narrativa, é uma sugestão e não propriamente uma negativa feita pelo discurso. Ele eleva ao plano da forma uma resposta ao conteúdo racista. Caberia se questionar, então, sobre a importância da montagem na escrita de Salim Miguel. Os comentários de Didi-Huberman (2012, p. 215) sobre a obra de Benjamin auxiliam, quando mostra que a fotografia, técnica moderna que surge no contexto da reprodutibilidade técnica, acaba por afetar todo o campo estético, no qual a arte passa a conter um componente 
fotográfico; escreve: "é preciso recordar que, para Benjamin, a idade da imagem nos anos 30 é, antes de tudo, a da fotografia: não a fotografia como aquilo que foi caritativamente admitido no território das belas artes ('a fotografia como arte'), mas sim a fotografia como aquilo que modifica de cabo a rabo essa mesma arte ('a arte como fotografia')".

Ou seja, a fotografia como uma nova arte, propriamente moderna e pós-aurática, acaba por afetar toda a produção estética e, formalmente, aproxima-se também de uma nova forma narrativa, o conto como gênero - ligado a certa ideia de cena, um recorte, uma imagem, quando pensado em relação ao romance. E daí também a montagem, técnica cinematográfica que passa a elemento narrativo e que assume centralidade nesse conto de Salim, pois, ao mimetizar a estrutura dual da cidade, abre espaço para que sua crítica seja elaborada por aquilo que não é componente do texto, mas que se dá nas passagens, nas ligações, nas conexões e sobreposições entre uma voz e outra.

Assim, vemos a dimensão desse processo mimético da estrutura da cidade na narrativa de Salim Miguel que, além de expressar a dualidade "oficial", a batalha das elites entre a UDN e o PSD, mostra também, por meio da montagem, a presença do componente modernista, o Grupo Sul, que, simbolicamente, aparece como aquilo que "não é ouvido", já que não é discurso, senão forma, algo que expressa, em verdade, o lugar social de exclusão que os jovens modernistas enfrentavam na cena intelectual da cidade; mas, ao mesmo tempo, só se pode entender o conto por meio daquilo que não se diz - algo, novamente, muito parecido ao necessário reposicionamento que Florianópolis enfrentou pós-Grupo Sul, não havendo hoje quem possa afirmar que Salim Miguel não seja o grande nome literário da cidade, ainda que em seu momento de estreia tenha aplacado uma série de disputas com a intelectualidade estabelecida, sendo inclusive levado ao cárcere quando do golpe de 1964.

O autor impõe um reconhecimento da proposta modernista cujo maior representante é ele mesmo por meio da estrutura formal de seu texto, em um processo no qual afirma o dual e se coloca, na forma, como oposição ao que seus personagens constroem.

Assim, se Salim aparentava projetar em um grupo social marginalizado a experiência de dualidade das elites, isso acaba por parecer, formalmente, como possibilidade de construção de uma crítica a esses mesmos grupos. $\mathrm{O}$ fato está relacionado ao processo de perder-se na cidade. $\mathrm{O}$ narrador-oficial, que se perde, não fala sobre as dificuldades de perder-se, sobre a chance de encontrar o desconhecido que ameaça, sobre construção de um sentido para si por meio do outro os temas de Benjamin (2017a) nos escritos sobre Berlim. Pelo contrário, ele não gosta do espaço no qual está, tem constante desejo de retornar ao hotel no qual vive, mas, por algum motivo, se detém, continua seguindo seu companheiro, o narrador-personagem que, mais do que observar o que vê, quer ter alguém que lhe escute enquanto verbaliza suas certezas. O que isso fala é de uma elite que ao mesmo tempo que, de alguma maneira, percebe a emergência de uma nova questão social (o urbano, a presença negra, os imigrantes), não consegue com esta se relacionar, tudo the parecendo muito diferente de si mesma e, no processo, afirmando uma certeza do passado: a migração açoriana, tema de festejo do $1^{\circ}$ Congresso Catarinense de História, realizado em 1948, expressão máxima dos discursos afirmativos da açorianidade. Passa, observa, percebe mais ou menos, mas insiste em uma imagem de certeza de um ideal "pacífico" e "burguês" de família.

\section{Na metrópole}

É pela montagem, em um dos devaneios em meio à conversa com seu companheiro, que o narrador percebe que

começara a anoitecer. As luzes agora se acendiam de todo. Fantasias multicoloridas, exóticas, absurdas, passavam por nós. Os ranchos, os grupos heterogêneos, os blocos, e também os chefes de família pacíficos e burgueses, muito concentrados, levando a prole "para ver", todos se comprimindo. Beliscões nas moças, assobios, gritos; mãos erguidas, serpentinas, confetis, lança-perfumes (Miguel, 1981, p. 7).

Vejamos um fragmento algo extenso da crônica que Marques Rebelo ([1952] 2010, p. 220221), amigo e "padrinho" intelectual de Salim Miguel, dedica a Florianópolis: 
Mas Florianópolis melhorou nestes dois anos em que lá não ia [...]. A luz era uma vergonha! Quem perdesse uma abóbora no meio da rua, ficava sem ela. [...] E uma das suas espertezas era viver como uma nova espécie de vaga-lume. Só que os vaga-lumes verdadeiros usam a luz no rabinho e os florianopolitanos usavam a luzinha na mão lanterninha de pilha, frequentemente fracativa - para poder acertar o caminho de casa, porque afinal ir de noite dar uma olhada na praça é um vício que tem raízes extraordinárias e que não há de ser falta de luz que vá impedir. Agora tem luz decente, que permite a leitura, embora proíba o namoro. Mas como é preceito altamente moral esse de viver às claras, está tudo muito bem. E além de leitura e moral, o simpático habitante da ilha já se pode dar ao luxo sempre sonhado de ter rádio sem pilha, geladeira, batedeira, enceradeira e liquidificador, embora não haja muita fruta para liquefazer.

Embora Rebelo seja um dos responsáveis pela recepção da obra do florianopolitano no Rio de Janeiro, existe uma nítida diferença na interpretação da modernização de Florianópolis entre os escritos dos dois autores. Rebelo parece reforçar uma chave de leitura que privilegia o atraso das periferias brasileiras em detrimento da então capital federal, o Rio de Janeiro. O tom cômico com o qual trata a iluminação e a chegada de eletrodomésticos à Ilha de Santa Catarina é mais ou menos comum em suas crônicas sobre o interior do país, compiladas em Cenas da vida brasileira, marcadas pelo atraso como chave de análise.

Claro que isso está intrinsecamente atrelado ao tom irônico das crônicas que compõem as Cenas da vida brasileira. Não que a ironia, como figura de linguagem, seja necessariamente antialegórica. Em Baudelaire, Benjamin (2017b) encontra ambos os elementos. Na própria obra de Rebelo ela ganha importância na novela O simples coronel Madureira (Rebelo, 2003), que, como crítica ao primeiro momento da ditadura civil-militar (pré AI-5, publicada em 1967), constitui, ironicamente, um personagem pífio, impotente, posto à frente de uma repartição estatal. A esta personagem, o coronel Madureira, chegam grandes quantidades de documentos que deve firmar. Assina sempre acreditando que está em uma promoção de seu trabalho, nunca refletindo que seus superiores talvez não gostariam de se comprometer com eles. Aqui, a ironia beira ao absurdo de Beckett, certa aceitação desmedida do que está posto; e enquanto tal apresenta potencial narrativo de percepção do social.

Nas Cenas..., entretanto, o tom é outro. A ironia está atrelada a uma ideia de progresso que tem, em seu par, uma de atraso. A província em detrimento da metrópole. A ideia de ironia desenvolvida por Susan Sontag (1993, p. 168) em O amante do vulcão parece prudente: "A ironia é a resposta padronizada do gentleman inglês expatriado à esquisitice, à rudeza dos nativos entre os quais é obrigado (mesmo que por escolha própria) a viver. Ser irônico é uma maneira de mostrar nossa superioridade sem ser mal-educado a ponto de indignar-se. Ou ofender-se". O tom de Rebelo na crônica destinada a Florianópolis parece mais ligado a essa defesa de sua superioridade, a percepção do outro como estranho, como outro, propriamente. Pela projeção de uma "metrópole" como modelo e de uma "periferia" como atraso, falta a Rebelo muito da dialética instaurada por Antonio Candido (1975) em Os parceiros do Rio Bonito; dialética esta que, ao entender os processos dentro de sua estrutura, não cai em uma projeção de um ideal progressista que não responde ao contexto material da experiência cultural - a pedra no caminho da crônica de Rebelo.

O movimento de Salim caminha em direção contrária. Reconhece as mudanças do urbano, percebe a existência de novas práticas de sociabilidade ("as luzes agora acendiam de todo", os "beliscões nas moças"), mas faz isso por meio de uma sutileza que não bloqueia a imagem em um único símbolo possível. Rebelo prescreve o fim dos namoros na praça por conta da iluminação, Salim percebe os beliscões apaixonados nas moças, sugerindo paqueras e namoros às escondidas. Há aqui uma tentativa de deixar entreaberta a possibilidade da interpretação por meio da sutileza de sua construção. Em Salim não há propriamente uma alegoria nos termos benjaminianos (2016), mas um componente que lhe é importante e que está ligado ao não bloqueio da imagem a um único símbolo. Ao não reduzir a relação a uma ação de causa e efeito, como as luzes que impossibilitariam os namoros (Rebelo), Salim permite que a cidade se expresse pelo tempo e pela ambiguidade, na qual esses "beliscões" são mais sugestões de uma 
trama escondida das famílias "pacíficas" e "burguesas", uma trama que talvez rompa justamente com o caráter normativo da imposição familiar.

A própria terminologia, as famílias "pacíficas" e "burguesas", merece reflexão. Ivonete Pereira assume uma perspectiva não de compreensão da modernização de Florianópolis, mas tem como preocupação entender as resistências e empecilhos que se colocaram a esse projeto. Dedicando-se à prostituição, aponta àquilo que era estigmatizado, ao mesmo tempo que integrante da experiência social. Assim, para a autora, é interessante reparar como, no bojo de "políticas públicas voltadas para a disciplinarização das camadas populares, as prostituas foram alvos exemplares, pois elas, além de pertencerem, em sua maioria, às camadas populares, traziam da atividade à qual se dedicavam o estigma que remontava aos mitos e símbolos criados pela moral burguesa" (Pereira, 2004, p. 21).

Podemos levar a afirmação ao conto de Salim, como quando deixa entrever as metáforas do carnaval, como os "beliscões" escondidos, que sugerem namoros no espaço urbano. Parece existir, ao fundo da narrativa, uma série de incertezas que apontam para a abertura do significante, mas que também deixam ver pela montagem as incompletudes de certa proposta de controle e disciplinamento dos corpos no movimento civilizatório engendrado pelas elites. Assim, as famílias pacíficas e burguesas têm seus propósitos incompletos, questionados, confrontados. Eles se apresentam, na narrativa, como ambiguidade, impossibilidade, mas também com algo de estupidez, em uma tentativa desenfreada de exercer um controle que nunca é absoluto.

É por consequência dessa ambiguidade e desse movimento de percepção que o texto não cai em anacronismo quando, duas décadas depois, em 1973, Beto Stodieck escreve que

Ora ora ora, onde estamos? Então foi só iluminar feéricamente a praça XV e aquilo transformou-se num felliniano palco? Não, não estou falando dos "atores" que fazem a freqüência diurna, longe disso. Nem nos amenos cavalheiros que anoitecem no local. Mas passem, repassem, olhem, reolhem, vejam e revejam o que está acontecendo depois que as bruxas tomam conta da cidade. [...] A Praça transformou-se num lantejoulado carrosel de bonecas vivas, vivíssimas. Os engraçados rapazzzzzessss da noite, com seus dotes de modelos e vozitas de soprano, fazem as mais variadas poses para os mais variados espectadores. Para cada um tem um gritinho, um gracejo, uma só graça pra quem vier e der. Atenção, atenção: não percam. Em cartaz o mais popular, o mais maaaaaravilhoso show de travesti do sul do mundo (Stodieck, 1999, p. 237)

Fim

O encerramento do texto expressa boa síntese do que foi a narrativa, composta por sobreposições que dão por meio da montagem a possibilidade de entrever a cidade em sua modernização: em um bar, entre cervejas e salgados, o personagem-narrador retira um pedaço de papel do bolso, no qual escreveu uma das pérolas de Espiridião Facada ao pedir dinheiro emprestado. Mas isso, que desde o princípio era o central da narrativa, pouco importa:

Terminara [de ler]. Devolvi [o papel no qual a história estava escrita]. Meu companheiro ficou me olhando. Eu nada disse. Nem ele. Aguardávamos ambos...

O bar se esvaziara. Só alguns bêbados jaziam derreados sobre as mesas. O gerente conferia o dinheiro. Garçons bocejavam.

Longe, contraditoriamente triste, pressago, soa o estribilho

"Unidos da lagoa

Somos da folia...

Quem quiser brincar

Guente té o outro dia..."

E

"Nós somos da princesa os unidos os únicos queridos..."

soa mais longe, sumindo, noutra voz, contrapontística (Miguel, 1981, p. 18). 


\section{Referências}

ARAUJO, Hermetes Reis de (1989). A invenção do litoral: reformas urbanas e reajustamento social em Florianópolis na primeira república. 1989. Dissertação (Mestrado em História) - Pontifícia Universidade Católica, São Paulo.

BENJAMIN, Walter (2016). Origem do drama trágico alemão. Tradução de João Barrento. Belo Horizonte: Autêntica.

BENJAMIN, Walter (2017a). Rua de mão única: infância berlinense: 1900. Tradução de João Barrento. Belo Horizonte: Autêntica.

BENJAMIN, Walter (2017b). Sobre alguns motivos na obra de Baudelaire. In: BENJAMIN, Walter. Baudelaire e a modernidade. Tradução de João Barrento. Belo Horizonte: Autêntica Editora.

BENJAMIN, Walter (2019). Sobre o conceito de história. In: BENJAMIN, Walter. O anjo da história. Tradução de João Barrento. Belo Horizonte: Autêntica.

CABRAL, Oswaldo Rodrigues (1979). Nossa Senhora do Desterro: memórias. Florianópolis: Lunardelli.

CANDIDO, Antonio (1975). Os parceiros do Rio Bonito. São Paulo: Livraria Duas Cidades.

CARDOSO, Fernando Henrique (2000). Negros em Florianópolis: relações sociais e econômicas. Florianópolis: Insular.

CASCAES, Franklin (2008). Crônicas de Cascaes. Florianópolis: Fundação Franklin Cascaes. v. 1.

CASCAES, Franklin (2012). O fantástico na Ilha de Santa Catarina. Florianópolis: EdUFSC.

D’EÇA, Othon Gama (2008). Homens e algas. 5. ed. Florianópolis: EdUFSC.

DIDI-HUBERMAN, George (2012). Quando as imagens tocam o real. Tradução de Patícia Carmello e Vera Casa Nova. PÓS, v. 2, n. 4, p. 206-219.

DIDI-HUBERMAN, George (2017). Povos expostos, povos figurantes. Tradução de Maria da Luz Correia. Vista, n. 1, p. 16-31.

FLORES, Maria Bernardete Ramos (1997). A Farra do Boi: palavras, sentidos, ficções. Florianópolis: EdUFSC.

MIGUEL, Salim (1981). Velhice e outros contos. Florianópolis: FCC.

MIGUEL, Salim (1994). Primeiro de abril: narrativas da cadeia. Rio de Janeiro: José Olympio.

MIGUEL, Salim (2000). Nur na escuridão. Rio de Janeiro: Topbooks.

MOTTA, Flávia de Mattos (2015). Sonoro silêncio: história e etnografia do aborto. Ponta Grossa: Todapalavra.

PEREIRA, Ivonete (2004). As decaídas: prostituição em Florianópolis (1900-1940). Florianópolis: EdUFSC.

RAMOS, Átila (1997). Carnaval da ilha. Florianópolis: Papa Livro.

RAMOS, Sebastião (1999). No tempo do Miramar. Florianópolis: Editora Papa-Livro.

REBELO, Marques (2003). O simples coronel Madureira. Rio de Janeiro: Nova Fronteira.

REBELO, Marques (2010). Florianópolis. In: REBELO, Marques. Cenas da vida brasileira. Rio de Janeiro: José Olympio.

SARLO, Beatriz (2004). La imaginación técnica: sueños modernos de la cultura argentina. Buenos Aires: Ediciones Nueva Visión.

SARLO, Beatriz (2013). Sete ensaios sobre Walter Benjamin e um lampejo. Tradução de Joana Angélica d'Avila Melo. Rio de Janeiro: Editora da UFRJ.

SCHWARZ, Roberto (2014). O sentido histórico da crueldade em Machado de Assis. In: SCHWARZ, Roberto. As ideias fora do lugar: ensaios selecionados. São Paulo: Penguin-Companhia.

SIMMEL, Georg (2005). As grandes cidades e a vida do espírito. Tradução de Leopoldo Waizbort. Mana, v. 11, n. 2, p. 577-591. 
SONTAG, Susan (1993). O amante do vulcão. Tradução de Isa Mara Lando. São Paulo: Companhia das Letras.

STODIECK, Beto (1999). Na Praça XV, o carrossel da boneca viva. In: PORTO, Bea; LAGO, Fernanda (Org.). É tudo mentira: a história segundo Beto Stodieck. Florianópolis: Verde Água Produções Culturais.

TRAMONTE, Cristiana (1995). A pedagogia das escolas de samba de Florianópolis: a construção da hegemonia cultural através da organização do carnaval. Dissertação (Mestrado em Educação) - Universidade Federal de Santa Catarina, Florianópolis.

VIEIRA, Alexandre Sardá (2010). Sessão das moças: história, cinema, educação (Florianópolis: 1943-1962). Tese (Doutorado em História) - Universidade Federal de Santa Catarina, Florianópolis.

\section{Nota}

O manuscrito é um aprofundamento de reflexões originadas no trabalho de conclusão de licenciatura em Ciências Sociais intitulado Fragmentos de uma educação para o moderno na Florianópolis de Salim Miguel, elaborado por Natan Schmitz Kremer sob orientação do prof. dr. Alexandre Fernandez Vaz e defendido em 2019 na Universidade Federal de Santa Catarina. Disponível em: https:/ / bit.ly/3kRi7HD 